\title{
Erratum to: Vasodilatory Mechanisms of Beta Receptor Blockade
}

\author{
Géraldine Rath • Jean-Luc Balligand • Chantal Dessy
}

Published online: 15 August 2012

(C) Springer Science+Business Media, LLC 2012

Erratum to: Curr Hypertens Rep (2012) 14:310-317

DOI 10.1007/s11906-012-0278-3

The original version of this article contained errors in the author byline and information. The corresponding author's given name and surname were reversed. The correct author byline and information is presented here.

The online version of the original article can be found at http://dx.doi.org/ 10.1007/s11906-012-0278-3.

G. Rath $\cdot$ J.-L. Balligand $\cdot$ C. Dessy $(\bowtie)$

Pole de Pharmacologie et Thérapeutique (FATH),

Institut de Recherche Expérimentale et Clinique (IREC),

Université catholique de Louvain,

B01.5309, Avenue Mounier 52,

1200 Brussels, Belgium

e-mail: chantal.dessy@uclouvain.be

G. Rath

e-mail: geraldine.rath@uclouvain.be

J.-L. Balligand

e-mail: jl.balligand@uclouvain.be

J.-L. Balligand

Cliniques Universitaires Saint-Luc,

Université catholique de Louvain,

B01.5309, Avenue Mounier 52,

1200 Brussels, Belgium 